\title{
Base Metal Ion Extraction and Stripping from WEEE Leachate by Liquid-liquid Extraction
}

\author{
Amir Talebi, ${ }^{1}$ Alessandra Cesaro, ${ }^{2}$ Alessandra Marra, ${ }^{2}$ Vincenzo Belgiorno ${ }^{2}$ \\ and Norli Ismail ${ }^{1 *}$ \\ ${ }^{1}$ School of Industrial Technology, Universiti Sains Malaysia, \\ 11800 USM Pulau Pinang, Malaysia \\ ${ }^{2}$ Sanitary Environmental Engineering Division, Department of Civil Engineering, \\ University of Salerno, 84084 Fisciano, Italy \\ *Corresponding author: norlii@usm.my
}

Published online: 25 October 2018

To cite this article: Talebi, A. et al. (2018). Base metal ion extraction and stripping from WEEE leachate by liquid-liquid extraction. J. Phys. Sci., 29(Supp. 3), 15-28, https://doi. org/10.21315/jps2018.29.s3.3

To link to this article: https://doi.org/10.21315/jps2018.29.s3.3

\begin{abstract}
The simultaneous effect of differentfactors such as $\mathrm{pH}$, carrier concentrations, organic phase modifier, and stripping agent concentrations on the extraction and stripping of base metals from waste electrical and electronic equipment (WEEE) leachate was investigated. Initially, sulphuric acid and hydrogen peroxide were used in the leaching process of base metals from WEEE, followed by an investigation on the effectiveness of different organic phases on WEEE leachate regarding metal extraction. In this phase, Versatic 10 (V10) and tributyl phosphate (TBP) were used as carrier and phase modifier, respectively, while kerosene was used as the organic phase diluent. Extractions of silver, copper, cadmium, nickel, iron, lead, zinc and aluminium were achieved using $150 \mathrm{~mm}$ of V10, loaded with $100 \mathrm{~mm}$ of TBP in kerosene. Eventually, a study on extracted metals stripping was carried out to optimise the highest base metal stripping from the organic phase. For this purpose, different concentrations of sulfuric acid were used as stripping agent, and the results revealed that $1.5 \mathrm{M}$ of $\mathrm{H}_{2} \mathrm{SO}_{4}$ successfully stripped the extracted metal ions.
\end{abstract}

Keywords: Base metals, solvent extraction, Versatic 10, waste electrical and electronic equipment, WEEE 


\section{INTRODUCTION}

The waste electrical and electronic equipment (WEEE) production is increasing rapidly in recent years. About 30-50 million tons of WEEE is disposed of each year, with an estimated annual growth rate of $3 \%-5 \%{ }^{1}$ In 2014 , around 9.5 million tons of WEEE were estimated to have been generated in the European Union (EU) and 41.8 million tons worldwide. ${ }^{2}$ Amongst the various components existing in WEEE (such as plastics, rubbers, ceramics, etc.), the presence of base metals in enormous proportion makes WEEE simultaneously a noticeable source of hazardous materials as well as a potential secondary source of metals.,4 Physical and chemical processes have been employed for the recycling of metals from WEEE. The electronic waste is first mechanically treated to separate the nonmetallic fraction from the metallic one. The latter is then further processed using high-temperature treatments, namely pyrometallurgical treatments, or leachingbased processes known as hydrometallurgical treatments. Due to its advantages of being lower costs and higher efficiency, hydrometallurgy has recently received a great deal of attention as an effective method to extract metals from WEEE. A hydrometallurgical process involves the dissolution of metals into solution and the extraction of the metals of interest from the leachate. ${ }^{5}$ Since WEEE contains a wide range of metals, the research is currently directed towards the optimisation of these processes, especially about the treatment methods which are capable of the selective recovery of metals.

Liquid-liquid extraction (LLE) has been used for the recovery of metals from various waste sources. ${ }^{6,7}$ LLE system consists of two phases, namely the aqueous phase and the organic phase. Aqueous phase refers to the part of the system which is loaded (contaminated) by a solute (solutes), and the organic phase is an immiscible liquid (diluent) in which the liquid extraction classification contains an extraction facilitator (carrier, extractant). ${ }^{8}$

This study investigates the effect of the organic phase containing Versatic 10 (V10) as a carrier in kerosene, on base metal extraction from WEEE leachate. Eventually, an investigation on the effectiveness of various sulphuric acid concentrations on the base metal stripping from the loaded organic phase is also presented. 


\section{EXPERIMENTAL}

\subsection{Chemicals and Materials}

WEEE shredding dust collected at a full-scale mechanical treatment plant was used for the experimental purposes. An amount of $20 \mathrm{~g}$ WEEE dust was subject to a leaching process using $160 \mathrm{ml}$ of $2 \mathrm{M} \mathrm{H}_{2} \mathrm{SO}_{4}$ and $40 \mathrm{ml} \mathrm{H}_{2} \mathrm{O}_{2}$. A jar test machine was used to keep the solution stirred at $150 \mathrm{rpm}$. After $3 \mathrm{~h}$, the leachate was filtered, and the aqueous phase was used for LLE experiments.

Decanoic acid (V10, $\geq 98 \%$ purity) and tributyl phosphate (TBP, $\geq 99 \%$ purity) supplied by Sigma Aldrich were used as the carrier and the phase modifier, respectively. Kerosene was used as a diluent and supplied by Honeywell. The $\mathrm{pH}$ was adjusted using hydrochloric acid and ammonium solution (30\%) while sulphuric acid was tested as a stripping agent. The organic phase was prepared by dissolving 50-250 mm of V10 plus 50-150 mm TBP in kerosene. Experiments involving the diluent without adding the carrier were carried out as well.

\subsection{Experimental Method}

Preliminary studies were carried out to evaluate and estimate the influential factors that could play a significant role in the metal extraction process. Three factors (carrier concentration, feed phase $\mathrm{pH}$ and phase modifier concentration) were tested between two levels to determine the highest metal ion extraction condition using a factorial design.

For the extraction phase, a volume $(10-50 \mathrm{ml})$ of the prepared organic phase was mixed with the prepared aqueous phase at a specific organic to aqueous phase ratio $(1: 1)$ in a conical flask. The bottles were shaken by a magnetic stirrer. Samples were taken after $2 \mathrm{~h}$ of stirring from the aqueous phase to determine the metal uptake from the aqueous phase into the organic phase. The aqueous phase $\mathrm{pH}$ was measured before and after each run with a $\mathrm{pH}$ meter.

The extraction efficiency (E\%) of metal ion was calculated according to the following equation:

$$
\mathrm{E} \%=\left(\frac{\left[\mathrm{M}_{\text {org }}^{2+}\right]}{\left[\mathrm{M}_{\text {ini }}^{2+}\right]}\right) \times 100
$$

where $\left[\mathrm{M}^{2+}\right]$ represents the concentration of metal ion and the subscripts org and ini denote organic and initial states, respectively. 
The organic phase with the highest extracted metal concentration was chosen for the further stripping studies in which different concentrations of $\mathrm{H}_{2} \mathrm{SO}_{4}$ were investigated to evaluate the highest stripping efficiency. The stripping procedure was similar to the extraction one, with the exception that the aqueous phase was the prepared aqueous stripping phase and the organic one consisted of the metal-loaded organic phase obtained after the extraction process. After the extraction process, the organic phase was thus separated and mixed with the stripping phase. $\mathrm{H}_{2} \mathrm{SO}_{4}$ with concentrations of $0.5 \mathrm{M}, 1.0 \mathrm{M}, 1.5 \mathrm{M}$ and $2.0 \mathrm{M}$ was used as stripping agent. Unlike the extraction procedure, in the stripping procedure, the $\mathrm{pH}$ adjustment after mixing the two phases was omitted.

During each experiment, samples were taken from the aqueous phase, filtered and diluted with distilled water using appropriate dilution factors and were analysed by inductively coupled plasma atomic emission spectroscopy for base metals (silver, copper, cadmium, nickel, iron, lead, zinc and aluminium) concentration measurements.

\section{RESULTS AND DISCUSSION}

\subsection{Metal Ion Extraction}

Results achieved from preliminary studies on the LLE revealed that in high acidic condition of raw leachate, the metal extraction is not satisfactory. However, by increasing the $\mathrm{pH}$ value from 5 to 8 , the metal concentration increased drastically, suggesting that the optimum $\mathrm{pH}$ value for metal-V10 complex formation is between 5 and 8 . A pH value of more than 8 caused metal hydroxide and precipitation formation whereas $\mathrm{pH}$ below 5 decreased the metal-carrier complex formation. These results are in good agreement with the general mechanism involving the chemical complexation of V10 and metals.

V10 with a chemical formula of $\mathrm{C}_{10} \mathrm{H}_{20} \mathrm{O}$ is a synthetic carboxylic acid containing an $\mathrm{O}-\mathrm{H}$ branch in the chemical structure which makes it a suitable extractant in solvent extraction. ${ }^{9}$ The general chemical reaction between metal divalent and V10 can be presented as below: ${ }^{10}$

$$
\mathrm{M}_{\mathrm{aq}}^{2+}+\mathrm{n}(\mathrm{RH})_{2} \leftrightarrows\left[\mathrm{MR}_{2} \mathrm{H}_{2 n-2}\right]_{\text {org }}+2 \mathrm{H}_{\mathrm{aq}}^{+}
$$

where RH represents the V10 molecular compound and $\mathrm{n}$ represents the number of carrier molecules involving in complexation reaction which for bivalent metals extraction is equal to 2 . 
According to Equation 2, complexation between the metal ion and V10, which occurs at the aqueous/organic interface, leads to release of $\mathrm{H}^{+}$from the organic phase into the aqueous phase, and as a consequence, a drop in $\mathrm{pH}$ value is expected.

Equation 2 shows that the feed phase $\mathrm{pH}$ plays an essential role in the metal extraction process. However, it should be taken into account that since metal species show great intense for metal-hydroxide formation and precipitation, it is vital to determine the maximum $\mathrm{pH}$ value of the extraction process to avoid undesired metal-hydroxide formation. For this purpose, extraction reaction of a metal species by carrier loaded in aliphatic organic solvents can be presented as: ${ }^{11}$

$$
\mathrm{M}_{\mathrm{aq}}^{\mathrm{a}+}+\left[\frac{\mathrm{a}+\mathrm{b}}{2}\right]\left(\mathrm{RH}_{2(\text { org })}\right) \rightleftharpoons \mathrm{MR}_{\mathrm{a}}(\mathrm{RH})_{\mathrm{b}(\text { org })}+\mathrm{aH}_{\mathrm{aq}}^{+}
$$

where the valence of metal species (a) and the number of carrier molecules engaged in the reaction (b) are used as the stoichiometric coefficient of the Equation 2. By increasing the $\mathrm{pH}$, the equilibrium position moves to the right and thus, produces more metal-organic complexes. On the other hand, as the $\mathrm{H}^{+}$ concentration increases, the equilibrium position shifts to the left and less metalorganic complexes are produced. The maximum permissible $\mathrm{pH}$ of solution can be calculated based on the solubility product constant $\left(\mathrm{K}_{\mathrm{sp}}\right)$ of metal hydroxides, to avoid the formation of metal hydroxide at low $\mathrm{H}^{+}$concentrations: ${ }^{12}$

$$
\mathrm{K}_{\mathrm{sp}}=[\mathrm{M}]^{\mathrm{a}+}[\mathrm{OH}]^{-\mathrm{a}}
$$

For instance, the initial concentration of cadmium in the WEEE leachate was around $28 \mathrm{mg} \mathrm{l}^{-1}(0.25 \mathrm{~mm})$. As the solubility product constant $\left(\mathrm{K}_{\mathrm{sp}}\right)$ of cadmium hydroxides at $298 \mathrm{~K}^{\circ}$ is $7.2 \times 10^{-15}$, by applying these factors in Equation 4, the concentration of $\left[\mathrm{OH}^{-}\right]$can be calculated as:

$$
\left[\mathrm{OH}^{-}\right]=\sqrt{28.12 \times 10^{-12}}
$$

The $\left[\mathrm{OH}^{-}\right]$obtained at a specific $\mathrm{K}_{\mathrm{sp}}$ can be then used to determine the maximum permissible $\mathrm{pH}$ of the solution according to the following:

$$
\mathrm{pH}=14+\log \left[\mathrm{OH}^{-}\right]
$$

which is equal to 8.73 .

Figure 1 shows the simultaneous effect of $\mathrm{pH}$ and [V10] on silver extraction. It was revealed that silver extraction from the WEEE leachate follows the same pattern 
for each stage. The extraction for silver shows a peak when the experiment runs at the middle level of each factor $(\mathrm{pH}=6$ and $[\mathrm{V} 10]=150 \mathrm{~mm})$, while the highest extraction of $85 \%$ occurs at $\mathrm{pH} 7$ and $200 \mathrm{~mm}$ [V10]. Similar extraction behaviour was observed for copper (Figure 2), in accordance with the previous investigations reported in the literature, while the extraction behaviour for aluminium and iron showed an opposite trend. ${ }^{13}$ As presented in Figure 3 and Figure 4, it was observed that once the initial $\mathrm{pH}$ of the aqueous phase is set at 7 , the highest aluminium extraction takes place regardless of the carrier concentration. On the other hand, if both factors ( $\mathrm{pH}$ and [V10]) are in their corresponding middle level (6 $\mathrm{mm}$ and $150 \mathrm{~mm}$, respectively), the aluminium extraction decrease drastically. These results suggest that the observed aluminium removal is mainly due to $\mathrm{pH}$ change rather than extraction process. Similar findings are reported by using V10 as carrier and $\mathrm{NaOH}$ for $\mathrm{pH}$ adjustment. ${ }^{14}$ Figure 5 to Figure 8 show that the highest extraction of zinc, lead, cadmium and nickel occurred in $6<\mathrm{pH}<7$ when [V10] is fixed at $150 \mathrm{~mm}$, with a relatively similar pattern of extraction.

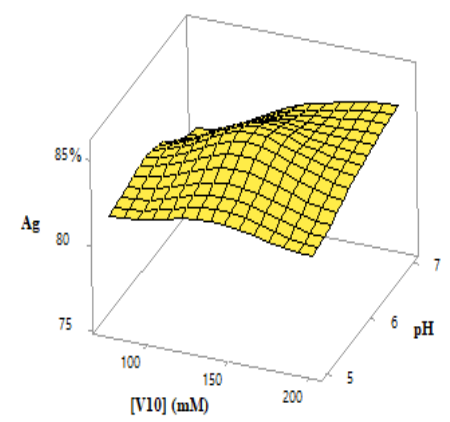

Figure 1: Three-dimensional plot of silver extraction as function of $\mathrm{pH}$ and [V10].

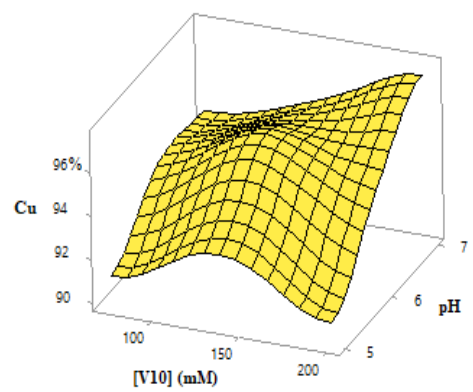

Figure 2: Three-dimensional plot of copper extraction as function of $\mathrm{pH}$ and [V10]. 


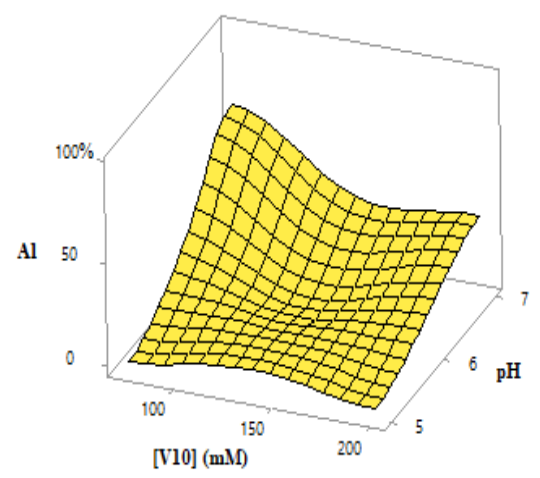

Figure 3: Three-dimensional plot of aluminium extraction as function of $\mathrm{pH}$ and [V10].

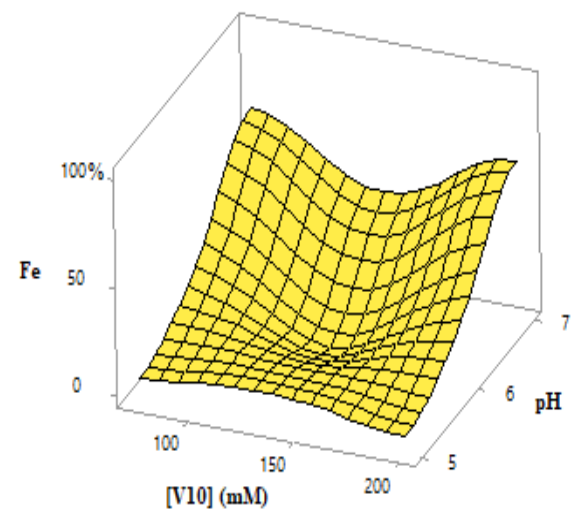

Figure 4: Three-dimensional plot of iron extraction as function of $\mathrm{pH}$ and [V10]. 


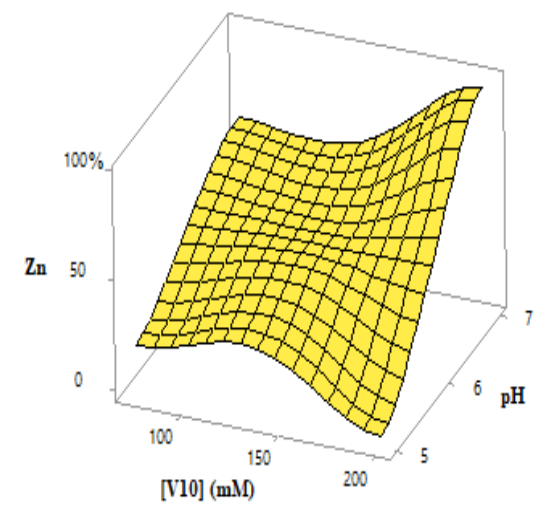

Figure 5: Three-dimensional plot of zinc extraction as function of $\mathrm{pH}$ and [V10].

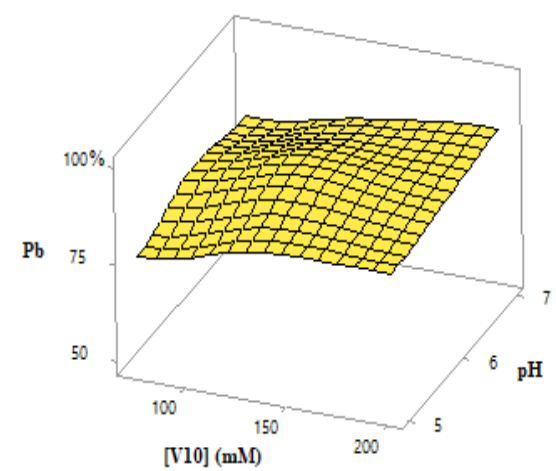

Figure 6: Three-dimensional plot of lead extraction as function of $\mathrm{pH}$ and [V10]. 


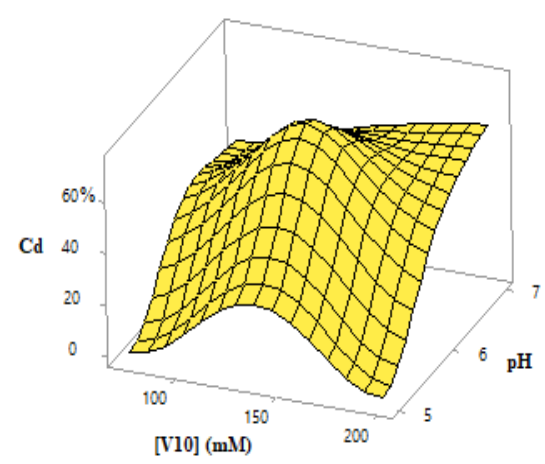

Figure 7: Three-dimensional plot of cadmium extraction as function of $\mathrm{pH}$ and [V10].

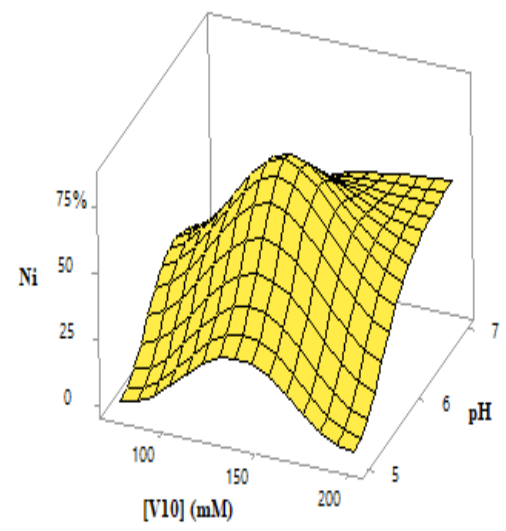

Figure 8: Three-dimensional plot of nickel extraction as function of $\mathrm{pH}$ and [V10].

Moreover, the results confirmed that using TBP as carrier individually does not affect metal extraction efficiency, while on the other hand it was observed that in the case of using the organic phase without TBP, the emulsion formation practically disables the aqueous/organic phase separation. According to literature studies, TBP has shown relatively low extraction capacity for metal extraction, but it is mostly used as a phase modifier by adduction with metal-carrier complexes in the organic phase. ${ }^{9,16,17}$ Phase modifiers are used to eliminate or reduce the organic phase emulsification. An emulsification of the organic phase happens due to lateral shear forces and is counted as an essential factor causing membrane instability. ${ }^{15}$

TBP improves metal extraction efficiency in co-operating with D2EHPA because tetrahedral or octahedral structure of metal-D2EHPA complex in the organic phase 
consists of four large extractant molecules in the coordination sphere and cause spherical hindrance. ${ }^{18-21}$ An extractant such as TBP with Lewis base properties, relatively smaller molecule and low extraction ability could be exchanged with two of these molecules..$^{22-24}$ Complexation reaction between metal cation and carrier ligand involves an initial formation of "inner sphere" in which water molecules that intervene metal carrier complexation and (replaced between metal and ligand molecules) have been displaced, and inner sphere metal-ligand complexes are formed. ${ }^{25}$ However, TBP due to being an "outer sphere" ligand, is unable to expulse inner water molecules of metal-ligand complex and hence complexation termination causes low extractability of TBP. ${ }^{26}$

\subsection{Metal Ion Stripping}

Figure 9 shows the effect of sulphuric acid on metal stripping from the organic phase. Since sulphuric acid, a strong acid, is capable of losing a proton $\left(\mathrm{H}^{+}\right)$and being ionised (dissociated) in the stripping phase more than other mineral acids, the highest stripping percentage was obtained between $1.0 \mathrm{M}$ and $1.5 \mathrm{M}^{\circ} \mathrm{H}_{2} \mathrm{SO}_{4}$. The low concentration of $\mathrm{H}_{2} \mathrm{SO}_{4}$ (below $1.0 \mathrm{M}$ ) did not show enough strength to strip off the metals existing in the organic, while once the sulfuric acid is between $1.0 \mathrm{M}<\left[\mathrm{H}_{2} \mathrm{SO}_{4}\right]<2.0 \mathrm{M}$, it has the highest stripping efficiency. The higher concentration of $\mathrm{H}^{+}$would shift the equilibrium of Equation 2 more to the left and, resulting in higher stripping percentage, but if the concentration of the stripping agent is beyond $2.0 \mathrm{M}$, it will increase water permeability in the organic/stripping interface, leading to obvious swelling due to high osmotic pressure gradient between the stripping phase and the organic phases, and consequently less metal stripping efficiency. ${ }^{27}$

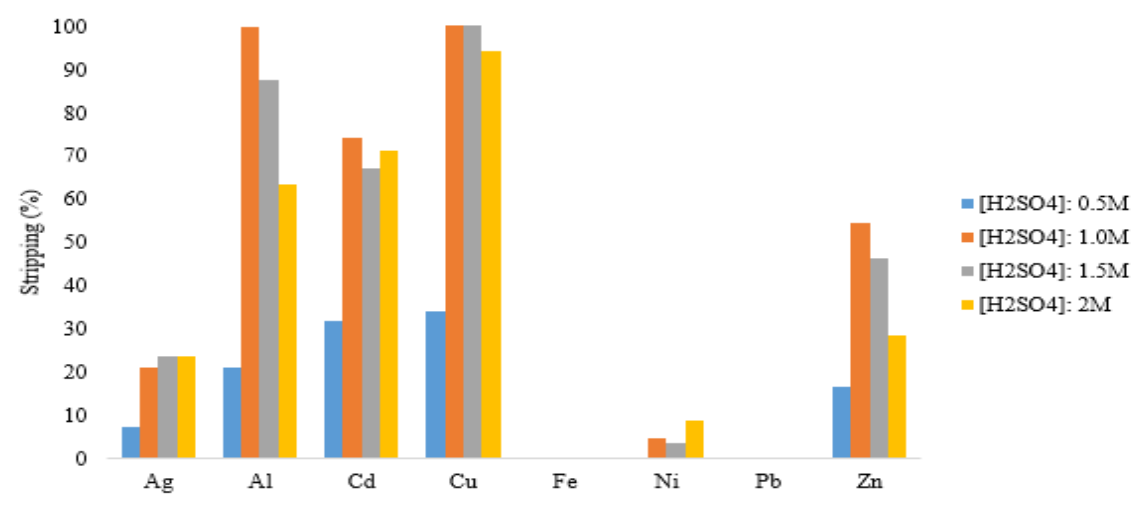

Figure 9: Metal stripping efficiency versus various stripping agent concentrations. 
Using $\mathrm{H}_{2} \mathrm{SO}_{4}$ as stripping agent is entirely accepted among several researchers for metal extraction by the dimeric carrier in aliphatic solvents while exceptionally it is reported that $\mathrm{HCl}$ efficiency for stripping of copper extraction system is preferred over $\mathrm{H}_{2} \mathrm{SO}_{4}{ }^{28-31}$

\section{CONCLUSION}

An LLE process was carried out to recover base metals from WEEE dust leachate selectively. The combination of V10, TBP and kerosene was investigated. Simultaneous effect of the carrier, phase modifier and aqueous phase $\mathrm{pH}$ were analysed along with the efficiency of various sulphuric acid concentrations as the stripping agent. It was concluded that significant interaction between V10 and aqueous phase $\mathrm{pH}$ results in complete zinc, lead and copper recovery from the WEEE leachate solution. Furthermore, $85 \%$ of silver and $60 \%$ of cadmium were extracted efficiently, using $150 \mathrm{~mm}$ of V10, $100 \mathrm{~mm}$ of TBP and at $\mathrm{pH} 6$. It was also observed that during the extraction process and due to $\mathrm{pH}$ adjustment, massive quantities of aluminium and iron compound precipitated, resulting in a complete removal of both metals. It is suggested that TBP has a minor effect on metal extraction but has a significant role in preventing emulsion formation during the aqueous-organic stirring process. Finally, 1.5 M of sulfuric acid was found to strip the extracted metals at higher efficiencies.

\section{ACKNOWLEDGEMENTS}

The authors acknowledge the Sanitary Environmental Engineering Division (SEED), Department of Civil Engineering, the University of Salerno, Italy for providing all facilities. The study was funded through the Universiti Sains Malaysia (USM) research university grant (grant number 1001/PTEKIND/814239).

\section{REFERENCES}

1. Rafia, A. et al. (2013). Survey and analysis of public knowledge, awareness and willingness to pay in Kuala Lumpur, Malaysia: A case study on household WEEE management. J. Clean. Prod., 52, 185-193, https://doi. org/10.1016/j.jclepro.2013.02.004.

2. Baldé, C. P. et al. (2015). The global e-waste monitor. Bonn: United Nations University. 
3. Talebi, A. et al. (2012). Optimization of nickel removal using liquid-liquid extraction and response surface methodology. Desalin. Water Treat., 47, 334-3340, https://doi.org/10.1080/19443994.2012.696432.

4. Hagelüken, C. (2006). Recycling of electronic scrap at Umicore precious metals refining. Acta Met. Slovaca., 12, 111-120.

5. Cui, J. \& Zhang, L. (2008). Metallurgical recovery of metals from electronic waste: A review. J. Haz. Mat., 158, 228-256, https://doi.org/10.1016/j. jhazmat.2008.02.001.

6. $\mathrm{Li}, \mathrm{X}$. et al. (2014). Solvent extraction of vanadium from a stone coal acidic leach solution using D2EHPA/TBP: Continuous testing. Hydrometal., 154, 40-46, https://doi.org/10.1016/j.hydromet.2014.11.008.

7. Matsumiya, H., Kato, T. \& Hiraide, M. (2014). Ionic liquid-based extraction followed by graphite-furnace atomic absorption spectrometry for the determination of trace heavy metals in high-purity iron metal. Talanta, 119, 505-508, https://doi.org/10.1016/j.talanta.2013.11.057.

8. Dean, J. R. (1998). Extraction methods for environmental analysis. West Sussex: John Wiley \& Sons.

9. Rydberg, J. et al. (2004). Solvent extraction equilibria. In Rydberg, J. M. et al. (Eds.). Solvent extraction principles and practice. New York: Marcel Dekker, 109-120.

10. Zhu, T. (2005). Extraction and ion exchange. China: Metallurgical Industry Press.

11. Chang, S. H., Teng, T. T. \& Norli, I. (2011). Efficiency, stoichiometry and structural studies of $\mathrm{Cu}$ (II) removal from aqueous solutions using di-2ethylhexylphosphoric acid and tributyl phosphate diluted in soybean oil. Chem. Eng. J., 166, 249-255, https://doi.org/10.1016/j.cej.2010.10.069.

12. Wilson, A. M. et al. (2014). Solvent extraction: The coordination chemistry behind extractive metallurgy. Chem. Soc. Rev., 43, 123-134, https://doi. org/10.1039/C3CS60275C.

13. Jha, M. K., Kumar, V. \& Singh, R. J. (2001). Review of hydrometallurgical recovery of zinc from industrial wastes. Resour. Conser. Recy., 33, 1-2, https://doi.org/10.1016/S0921-3449(00)00095-1.

14. Sung, H. J. et al. (2016). Selective extraction and separation of nickel from cobalt, manganese and lithium in pre-treated leach liquors of ternary cathode material of spent lithium-ion batteries using synergism caused by Versatic 10 acid and LIX 84-I. Hydrometal., 159, 65-74, https://doi.org/10.1016/j. hydromet.2015.10.012.

15. Kocherginsky, N. M., Yang, Q. \& Seelam, L. (2007). Recent advances in supported liquid membrane technology. Sep. Purif. Technol., 53, 171-177, https://doi.org/10.1016/j.seppur.2006.06.022. 
16. Chang, S. H., Teng, T. T. \& Norli, I. (2010). Extraction of $\mathrm{Cu}(\mathrm{II})$ from aqueous solutions by vegetable oil-based organic solvents. J. Haz. Mat., 181, 868-872, https://doi.org/10.1016/j.jhazmat.2010.05.093.

17. Cheng, C. Y. (2000). Purification of synthetic laterite leach solution by solvent extraction using D2EHPA. Hydrometal., 56, 369-386, https://doi. org/10.1016/S0304-386X(00)00095-5.

18. Fatmehsari, D. H. et al. (2009). Interaction between TBP and D2EHPA during $\mathrm{Zn}, \mathrm{Cd}, \mathrm{Mn}, \mathrm{Cu}, \mathrm{Co}$ and Ni solvent extraction: A thermodynamic and empirical approach. Hydrometal., 98, 143-147, https://doi.org/10.1016/j. hydromet.2009.04.010.

19. Sato, T. \& Nakamura, T. (1972). The complexes formed in the divalent transition metal-sulphuric acid-di-(2-ethylhexyl)-phosphoric acid extraction systems-cobalt(II), nickel(II) and copper(II) complexes. J. Inorg. Nucl. Chem., 34, 3721-3730, https://doi.org/10.1016/0022-1902(72)80017-4.

20. Van de Voorde, I. et al. (2005). Influence of acetate ions and the role of the diluents on the extraction of copper (II), nickel (II), cobalt (II), magnesium (II) and iron (II, III) with different types of extractants. Hydrometal., 78, 92-106, https://doi.org/10.1016/j.hydromet.2005.02.008.

21. Gajda, B. \& Bogacki, M. B. (2007). The effect of tributyl phosphate on the extraction of nickel(II) and cobalt(II) ions with di(2-ethylhexyl)phosphoric acid. Physicochem. Probl. Miner. Process., 41, 145-152.

22. Choppin, G. R. (2004). Complexation of metal ions. In Rydberg, J. M. et al. (Eds.). Solvent extraction principles and practice. New York: Marcel Dekker, https://doi.org/10.1201/9780203021460.ch3.

23. Vahidi, E., Rashchi, F. \& Moradkhani, D. (2009). Recovery of zinc from an industrial zinc leach residue by solvent extraction using D2EHPA. Miner. Eng., 22, 204-206, https://doi.org/10.1016/j.mineng.2008.05.002.

24. Sarkar, R., Ray S. \& Basu, S. (2014). Synergism in solvent extraction and solvent extraction kinetics. J. Chem. Biol. Phys. Sci., 4, 3156-3181.

25. Brezonik. P. L. \& Arnold, W. W. (2011). Water chemistry: An introduction to the chemistry of natural and engineered aquatic systems. Oxford: Oxford University Press.

26. Mohapatra, P. \& Manchanda, V. (1999). The unusual extraction behavior of americium(III) and dioxouranium(VI) from picric acid medium using neutral oxodonors II: A thermodynamic study. J. Radioanal. Nucl. Chem., 240, 159-164, https://doi.org/10.1007/BF02349149.

27. Kislik, V. S. (2010). Emulsion liquid membranes: Definitions and classification, theories, module design, applications, new directions and perspectives. In Kislik, V. S. (Ed.). Liquid membranes: Principles and applications in chemical separations and wastewater treatment. Amsterdam: Elsevier, 142-199. 
28. Yi, J. \& Tavlarides, L. L. (1995). Modeling chemically active liquid membranes in tubular inorganic supports. AIChE. J., 41, 1403-1412, https:// doi.org/10.1002/aic.690410607.

29. Youn, I. J. et al. (1997). Analysis of Co-Ni separation by supported liquid membrane containing HEH-(EHP). J. Membr. Sci., 125, 231-236, https:// doi.org/10.1016/S0376-7388(96)00199-8.

30. Nazemi, M. K. \& Rashchi, F. (2012). Recovery of nickel from spent $\mathrm{NiO} / \mathrm{A} 12 \mathrm{O} 3$ catalyst through sulfuric acid leaching, precipitation and solvent extraction. Waste Manag. Res., 30, 492-497, https://doi. org/10.1177/0734242X11417984.

31. Ren, Z. et al. (2007). Extraction equilibria of copper(II) with D2EHPA in kerosene from aqueous solutions in acetate buffer media. J. Chem. Eng. Data, 52, 438-441, https://doi.org/10.1021/je060370o. 